\title{
The Feasibility of Radiolabeling for Human Serum Albumin (HSA) Adsorption Studies
}

\author{
AT VAN DER SCHEER,* JAN FEIJEN,* JAN KLEIN ELHORST,$\dagger$ \\ PAUL G.L.C. KRUGERS DAGNEAUX, $\dagger$ AND CEES A. SMOLDERS* \\ ${ }^{*}$ Department of Chemical Technology, Twente University of Technology, and $\dagger$ Department of Pharmacy \\ Stadsmaten Hospital, Enschede, The Netherlands
}

Received February 12, 1976; accepted January 26, 1978

\begin{abstract}
Human serum albumin (HSA) was labeled in various ways and with different radioactive labels (Technetium-99m and Iodine-125). Characterization with electrophoresis on polyacryl gel and immunoelectrophoresis did not reveal differences between labeled and nonlabeled HSA. The release of the label from labeled proteins in phosphate buffer ( $\mathrm{pH} \mathrm{7.4)} \mathrm{was} \mathrm{studied} \mathrm{as} \mathrm{a} \mathrm{function} \mathrm{of}$ time. ${ }^{125}$ I-labeled proteins were stable and ${ }^{99 m} \mathrm{Tc}$-labeled proteins showed different stabilities depending on the labeling method which was used. The adsorption behavior of labeled HSA and HSA onto polystyrene (PS) and silicon rubber (SR) was studied by using two methods. It appeared that all labeled HSA compounds showed a preferential adsorption onto PS (and SR) substrates. The ${ }^{99 m}$ Tc-labeled HSA showed a high value of the preferential adsorption factor $(\phi \geqslant 1)$. The $\phi$ value for ${ }^{125} \mathrm{I}$-labeled HSA was about 1.4. It was also shown that $\phi$ was dependent on the kind of substrate used. The methods developed to determine preferential adsorption of labeled proteins compared to their nonlabeled analogs are also generally applicable for different types of compounds.
\end{abstract}

\section{INTRODUCTION}

The development of improved bloodcompatible materials requires a better insight into the events which occur when a foreign material is contacted with blood. One of the initial events is the adsorption of a protein layer at the blood-material interface. This layer modifies the original surface and has a strong influence on subsequent phenomena such as platelet adhesion and blood coagulation $(1,2,4)$.

Several methods are available to perform protein adsorption studies. These are depletion techniques $(5-10)$, spectroscopic techniques, such as colorimetry $(1-13)$, ATR/ IR (14-17), CD (18), and ellipsometry (19$25)$, and radio labeling $(7,26-28)$. This last method seems to be a very elegant one, which offers the possibility of determining the simultaneous adsorption of different proteins onto a surface.
The work published up to now, however, hardly contains any information about the influence of the label and the labeling techniques on the protein adsorption data.

Protein adsorption studies with labeled proteins are only useful when the bond between the label and the protein molecule is stable under adsorption conditions and when the adsorption behavior of the labeled protein is identical with that of the nonlabeled protein.

These aspects have been investigated for ${ }^{99 \mathrm{~m}} \mathrm{Tc}$ - and ${ }^{125} \mathrm{I}$-labeled HSA (human serum albumin), prepared by different labeling procedures.

Two methods have been used to study the adsorption behavior of labeled HSA. The first method comprises the measurement of the adsorption isotherms of labeled proteins on PS (polystyrene) and SR (silicon rubber) from solutions containing different concentration ratios of labeled to nonla- 
beled protein. The second method consists of the simultaneous determination of the adsorption of labeled and nonlabeled protein on a PS latex, with a high specific surface area.

\section{THEORY OF ADSORPTION BEHAVIOR}

The application of radio-labeled protein in adsorption studies is only allowed when the labeling method or the label itself does not change the adsorption properties of the protein. Therefore the adsorption behavior of labeled protein molecules $\mathrm{A}$ has to be compared with nonlabeled protein molecules B, which differ from molecules A only in the label.

Once it has been established that there is no difference in adsorption between the labeled molecule $\mathrm{A}$ and the nonlabeled molecule $\mathrm{B}$, one can use the labeled molecules A in preferential adsorption studies with a completely different molecule $\mathrm{C}$. In the derivations given below B can then be replaced by $\mathrm{C}$.

A simple model, derived from adsorption/ desorption kinetics and assuming monolayer adsorption, is used for the description of the possible difference in adsorption behavior of $\mathrm{A}$ and $\mathrm{B}$.

The rates of adsorption of $A$ and $B$ are given by:

$$
\begin{aligned}
& n_{\mathrm{A}}=k_{\mathrm{A}}[A] \cdot L / M_{\mathrm{A}}(1-\theta) \\
& n_{\mathrm{B}}=k_{\mathrm{B}}[B] \cdot L / M_{\mathrm{B}}(1-\theta)
\end{aligned}
$$

where

$$
\begin{aligned}
n_{\mathrm{A}}, n_{\mathrm{B}}= & \text { the number of effective col- } \\
& \text { lisons of molecules } \mathrm{A} \text { and } \mathrm{B} \\
& \text { per unit of surface area and } \\
& \text { time, } \mathrm{m}^{-2} \mathrm{sec}^{-1} \\
k_{\mathrm{A}}, k_{\mathrm{B}}= & \text { proportionality constants, } \mathrm{m} \\
& \text { sec }^{-1} \\
{[A],[B]=} & \text { the concentrations of A and } \mathrm{B} \\
& \text { in the solution, } \mathrm{kg} \mathrm{m}^{-3} \\
M_{\mathrm{A}}, M_{\mathrm{B}}= & \text { molecular weights of } \mathrm{A} \text { and } \mathrm{B}, \\
& \text { kg mole } \\
\theta= & \text { fraction of total available sur- }
\end{aligned}
$$

face area, covered with $A$ and $B$

$\mathrm{L}=$ Avogadros number, mole $^{-1}$

and

$$
n_{\mathrm{A}} / n_{\mathrm{B}}=\left(k_{\mathrm{A}} \cdot M_{\mathrm{B}} / k_{\mathrm{B}} \cdot M_{\mathrm{A}}\right)[A] /[B]
$$

The rates of desorption of $A$ and $B$ are given by:

$$
\begin{aligned}
& P_{\mathrm{A}}=\left(1 / t_{\mathrm{A}}\right) \cdot L \cdot A_{\mathrm{s}} / M_{\mathrm{A}} \\
& P_{\mathrm{B}}=\left(1 / t_{\mathrm{B}}\right) \cdot L \cdot B_{\mathrm{S}} / M_{\mathrm{B}}
\end{aligned}
$$

$P_{\mathrm{A}}, P_{\mathrm{B}}=$ number of molecules $\mathrm{A}$ and $\mathrm{B}$ leaving the surface per unit surface area and time, $\mathrm{m}^{-2}$ $\mathrm{sec}^{-1}$

$t_{\mathrm{A}}, t_{\mathrm{B}}=$ mean residence time of $\mathrm{A}$ and $\mathrm{B}$ on the surface, $s$

$A_{\mathrm{s}}, B_{\mathrm{s}}=$ the amount of $\mathrm{A}$ and $\mathrm{B}$ adsorbed onto the surface, $\mathrm{kg} \mathrm{m}^{-2}$

and

$$
P_{\mathrm{A}} / P_{\mathrm{B}}=\left(t_{\mathrm{B}} \cdot M_{\mathrm{B}} / t_{\mathrm{A}} \cdot M_{\mathrm{A}}\right) A_{\mathrm{s}} / B_{\mathrm{s}} \cdot
$$

Three cases can be considered:

(i) The adsorption of $\mathrm{A}$ and $\mathrm{B}$ is irreversible. This means that molecules once adsorbed do not leave the surface, and the ratio $A_{s} / B_{\mathrm{s}}$ will depend on the ratio of the numbers of collisons. For constant $[A]$ and $[B]$ we find:

$$
A_{\mathrm{s}} / B_{\mathrm{s}}=\left(k_{\mathrm{A}} M_{\mathrm{B}} / k_{\mathrm{B}} M_{\mathrm{A}}\right) \cdot[A] /[B] .
$$

(ii) The adsorption of either $A$ or $B$ is irreversible. In this case the surface will be covered completely by the molecules which adsorb irreversibly.

(iii) The adsorption of $\mathrm{A}$ and $\mathrm{B}$ is reversible (Langmuir). Equilibrium will be reached when $n_{\mathrm{A}}=P_{\mathrm{A}}$ and $n_{\mathrm{B}}=P_{\mathrm{B}}$, so:

$$
n_{\mathrm{A}} / n_{\mathrm{B}}=P_{\mathrm{A}} / P_{\mathrm{B}} \text {. }
$$

From Eqs. [3], [6], and [8] the ratio $A_{\mathrm{s}} / B_{\mathrm{s}}$ is then found to be:

$$
A_{\mathrm{s}} / B_{\mathrm{s}}=\left(t_{\mathrm{A}} k_{\mathrm{A}} / t_{\mathrm{B}} k_{\mathrm{B}}\right)[A] /[B] .
$$

Hence we find, in general:

$$
A_{\mathrm{s}} / B_{\mathrm{s}}=\phi[A] /[B] .
$$


The proportionality factor $\phi$ will be a constant in the first and the third case mentioned above and infinite or zero in the second case.

In order to get information about the value of $\phi$ for a given system, measurements must be carried out with a constant concentration ratio, $[A] /[B]$ in the solution.

$$
[A] /[B]=C \text {. }
$$

The surface will be covered completely with adsorbed molecules when the sum of the surface fractions occupied by molecules $A$ and $B$ equals one.

$$
S_{\mathrm{A}} \cdot A_{\mathrm{s}}+S_{\mathrm{B}} \cdot B_{\mathrm{s}}=1
$$

where $S_{\mathrm{A}}, S_{\mathrm{B}}=$ the specific surface areas of $A$ and $B$ when the surface would be occupied by one of these species, $\mathrm{m}^{2} \mathrm{~kg}^{-1}$.

Assuming that the specific surface area of $A$ is $x$ times that of $B$

$$
S_{\mathrm{A}}=x S_{\mathrm{B}}
$$

the following expression can be derived, using Eqs. [12] and [13]:

$$
\begin{gathered}
B_{\mathrm{s}}=\left(1-x S_{\mathrm{B}} A_{\mathrm{s}}\right) / S_{\mathrm{B}} \\
A_{\mathrm{s}} / B_{\mathrm{s}}=A_{\mathrm{s}} S_{\mathrm{B}} /\left(1-x S_{\mathrm{B}} A_{\mathrm{s}}\right) .
\end{gathered}
$$

An expression for $A_{\mathrm{s}}$ is found from Eqs. [10], [11], and [15]:

$$
A_{\mathrm{s}}=C \phi /\left(S_{\mathrm{B}}(1+C \phi x)\right) \text {. }
$$

This expression shows the relationship between the directly measurable quantity $A_{\mathrm{s}}$ and the parameters $\phi$ and $x$. Equation [16] is, of course, valid only when the exposed surface is completely covered with molecules A and B. Using this expression it is also possible to determine the quantity $\phi x$, without knowing $\phi$ or $S_{\mathrm{B}}$.

This can be done by performing two series of measurements (adsorption isotherms) with different concentration ratios $C_{1}$ and $C_{2}\left(C_{2}>C_{1}\right)$. Each of these adsorption isotherms yields a maximum adsorp-

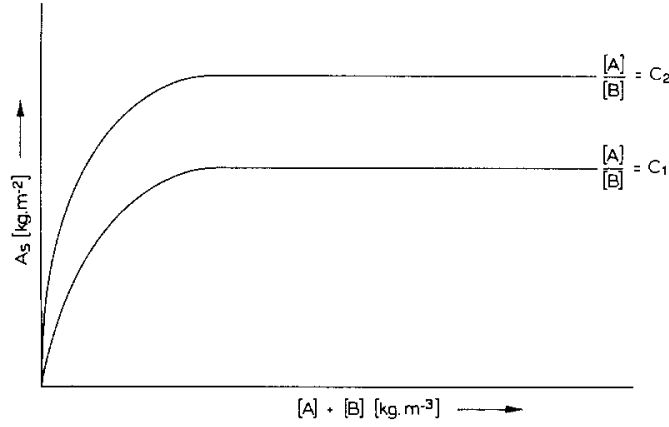

FIG. 1. Two hypothetical adsorption isotherms of labeled protein measured with concentration ratios $C_{1}$ and $C_{2}$

tion (plateau value) for $A_{\mathrm{s}}$, illustrated by Fig. 1.

The ratio of these two values is:

$A_{\mathrm{s}_{2}} / A_{\mathrm{s}_{1}}=y=\left(C_{2} / C_{1}\right)\left(1+C_{1} \phi x\right) /$

$$
\left(1+C_{2} \phi x\right)
$$

or

$$
\phi x=\left(1-y C_{1} / C_{2}\right) / C_{1}(y-1) . \quad[18]
$$

The specific surface area $S_{\mathrm{A}}$ can also be calculated from the two adsorption isotherms, via

$$
S_{\mathrm{A}}=\left(C_{2}-y C_{1}\right) /\left(\left(C_{2}-C_{1}\right) A_{\mathrm{s}_{2}}\right) .
$$

When $\phi x$ is determined by the method described above, we have to evaluate the uncertainty in $\phi x$, caused by the experimental error in $y$. Because the adsorption isotherms measured with radioactive proteins have an uncertainty in plateau value of about $5 \%$, the estimated error in $y$ becomes $0.1 y$.

The error in $\phi x$ which may arise from experimental error will be:

$$
\begin{gathered}
\Delta \phi x=\left|\left(\frac{\partial \phi x}{\partial C_{1}}\right)_{C_{2}, y}\right| \cdot \Delta C_{1} \\
\quad+\left|\left(\frac{\partial \phi x}{\partial C_{2}}\right)_{C_{1}, y}\right| \cdot \Delta C_{2} \\
+\left|\left(\frac{\partial \phi x}{\partial y}\right)_{C_{1}, C_{2}}\right| \cdot \Delta y .
\end{gathered}
$$

Taking $\Delta C_{1}$ and $\Delta C_{2}$ as zero, we obtain:

$$
\Delta \phi x=\left|\frac{C_{1}-C_{2}}{C_{1} C_{2}(1-y)^{2}}\right| \Delta y .
$$


For experimental reasons, $C_{2}$ will not exceed 0.1 or $\left|C_{1}-C_{2}\right|<0.1$. Since for values of $\phi x$ not too far from $1, y$ will be of the same order as $C_{2} / C_{1}$, and since $\Delta y \approx 0.1 y$ one finds that $\Delta \phi x \geq 1.0$.

This analysis shows that when only the adsorbed amount of radio-labeled protein can be measured, $\phi x$ cannot be determined accurately enough to exclude preferential adsorption (no preferential adsorption means $\phi x=1$ ).

When larger surface areas (PS latex) are used, the uncertainty in the determination of $A_{\mathrm{s}}$ will decrease. Moreover, it is possible to measure in addition the adsorbed amount of nonlabeled protein (depletion of protein in the solution). Up to this point we can conclude that $\phi$ can be measured directly, but not very accurately, using Eqs. $[10],[16]$, and [17], in a system with irreversible adsorption where the protein concentrations in solution do not change significantly upon adsorption, and if $S_{\mathrm{B}}$ in Eq. [16] is known from a separate experiment.

In the case of depletion experiments one should realize that protein concentrations decrease upon adsorption which influences $C$ when $\phi \neq 1$. In the case of reversible adsorption with depletion, there is no problem in using Eq. [10] to find $\phi$. When the adsorption of $A$ and $B$ is irreversible and depletion in solution occurs, one can still find $\phi$ using a different approach.

The rates of adsorption can be expressed as follows:

$$
\begin{aligned}
n_{\mathrm{A}} & =-\frac{d A}{d t} \cdot \frac{L}{M_{\mathrm{A}}} \times \frac{1}{S_{\mathrm{L}}} \\
& =k_{\mathrm{A}}[A] \cdot \frac{L}{M_{\mathrm{A}}}(1-\theta) \\
n_{\mathrm{B}} & =-\frac{d B}{d t} \cdot \frac{L}{M_{\mathrm{B}}} \times \frac{1}{S_{\mathrm{L}}} \\
& =k_{\mathrm{B}}[B] \cdot \frac{L}{M_{\mathrm{B}}}(1-\theta)
\end{aligned}
$$

where $S_{\mathrm{L}}=$ specific surface area of the latex, $\mathrm{m}^{2} \mathrm{~m}^{-3}$.

From Eqs. [22] and [23] we obtain:

$$
\frac{d B}{d A}=\frac{k_{\mathrm{B}}[B]}{k_{\mathrm{A}}[A]} \text {. }
$$

Integration gives:

$$
\frac{\ln \frac{A}{A_{0}}}{\ln \frac{B}{B_{0}}}=\frac{k_{\mathrm{A}}}{k_{\mathrm{B}}} .
$$

Using Eqs. [7] and [10], this expression for experiments with depletion in solution is related to the preferential adsorption factor $\phi$ without depletion:

$$
\frac{\ln \frac{A}{A_{0}}}{\ln \frac{B}{B_{0}}}=\phi \cdot \frac{M_{\mathrm{A}}}{M_{\mathrm{B}}}
$$

where $A_{0}, B_{0}=$ initial concentrations of $\mathrm{A}$ and $\mathrm{B}, \mathrm{kg} \mathrm{m}^{-3}$.

Although in the case of irreversible adsorption with depletion the straightforward use of Eq. [10] is not allowed to find $\phi$, one can define an experimental parameter $\phi_{\mathrm{dep}}$ to be found from:

$$
A_{\mathrm{s}} / B_{\mathrm{s}}=\phi_{\mathrm{depl}} \cdot A / B \text {. }
$$

The relation between $\phi$ and $\phi_{\text {depl }}$ can be given by:

$\phi_{\mathrm{depl}}=\frac{1-\left(B / B_{0}\right)^{\phi M_{\mathrm{A}} / M_{\mathrm{B}}}}{\left(B / B_{0}\right)^{\phi M_{\mathrm{A}} / M_{\mathrm{B}}}} \cdot \frac{B / B_{0}}{1-B / B_{0}}$

and

$$
\left|1-\phi_{\text {depl }}\right| \geq|1-\phi| \text {. }
$$

From Eq. [29] one sees that $\phi_{\text {depl }}$ gives an overestimation of the preferential adsorption factor. Only in cases when $\phi \rightarrow 1$ will $\phi_{\text {depl }} \rightarrow \phi$. For reversible adsorption $\phi_{\text {depl }}$ $=\phi$. It can be derived both from Eqs. [26] and [27] that the possible error in $\phi$ or $\phi_{\text {depl }}$, due to experimental errors, is about $8 \%$, on the basis of relative errors of $2 \%$ in the determined concentrations. 
III. MATERIALS AND METHODS

\section{Materials}

Human serum albumin (HSA) (crystalline) was obtained from Sigma, No. A 9511. ${ }^{99 m} T c$ was obtained from Philips Duphar. ${ }^{125} I$ (carrier free) was purchased from Amersham (IMS-30). Polystyrene (PS); $M_{\mathrm{w}}$ $=670,000, \quad \mathbf{M}_{\mathrm{w}} / \mathbf{M}_{\mathrm{n}}=1.15$, was obtained from Pressure Chemical Company, Pittsburgh, Mellon Institute Special Polystyrene Standard, lot. No. 13A. Stainless-steel squares (total surface area $3.2 \times 10^{-4} \mathrm{~m}^{2}$ ) were coated with PS by dipping in a solution of PS in toluene (7\%). The dipping procedure was repeated after several hours and the surfaces were dried during $15 \mathrm{hr}$ at $20^{\circ} \mathrm{C}$ temperature. PS latex was prepared by the method of Goodwin et al. (29). Particle diameter $0.56 \cdot 10^{-6} \mathrm{~m}, \zeta$ potential -72 $\mathrm{mV}$ in distilled water ( $\mathrm{pH} 7.0)$. Silastic Rubber (SR), Silastic sheeting, nonreinforced. Dow Corning Medical Grade Silicone Rubber, Subdermal Implant Material, lot. No. H 0 583. The sheeting was cut in square pieces (total surface area $2.0 \times 10^{-4}$ $\mathrm{m}^{2}$ ). Buffer was prepared by adding a solution of $0.01 M \mathrm{NaH}_{2} \mathrm{PO}_{4}$ and $0.15 \mathrm{M} \mathrm{NaCl}$ to a solution of $0.01 M \mathrm{NaOH}$ and $0.15 M$ $\mathrm{NaCl}$ until a pH of 7.4 was obtained.

All chemicals used were analytical grade.

Labeling of HSA. Labeling of HSA with ${ }^{99 \mathrm{~m}} \mathrm{Tc}$ was carried out by using:

(a) An incubation method $(30,31)$; this product is indicated as ${ }^{99 m}$ Tc-labeled HSA (i);

(b) A modified incubation method. This method is similar to method a, except for the $\mathrm{pH}$ during the incubation step $(\mathrm{pH}=7.4$ instead of 2); ${ }^{99 m}$ Tc-labeled HSA (im);

(c) An electrolytic method $(30,32,33)$; ${ }^{99 m}$ Tc-labeled HSA (e);

Labeling of HSA with ${ }^{125}$ I was carried out by using:

(d) An electrolytic method (34). This labeling was carried out at $\mathrm{pH} 7.4$ in buffer solution at $\mathrm{I}^{-}$concentrations lower than one $\mathrm{I}^{-}$ion per HSA molecule and a potential

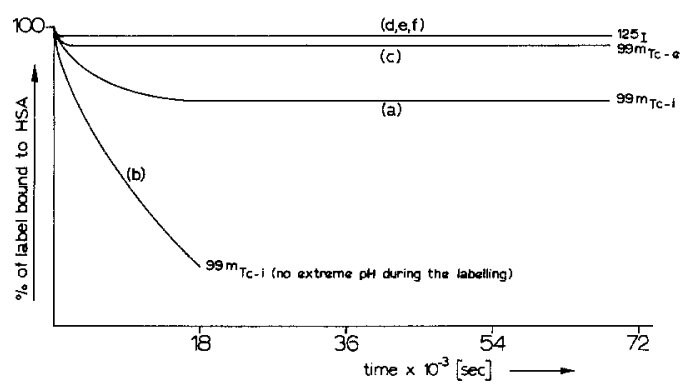

FIG. 2. Percentage of label bound to HSA as a function of time measured in buffer solution at $310^{\circ} \mathrm{K}$, $\mathrm{pH}=7.4,[\mathrm{NaCl}]=0.15 \mathrm{M}$; labeling methods $(\mathrm{a}-\mathrm{f})$.

difference between the cathode and the anode of less than $900 \mathrm{mV}$; ${ }^{125}$ I-labeled HSA (e).

(e) An electrolytic method (micro). In principle this method is similar to method d. This labeling was carried out in a microreaction cell designed by the IRI. ${ }^{1}$ In the cell the bottom $(\mathrm{Pt})$ acts as the cathode and a stirrer $(\mathrm{Pt})$ acts as the anode. The reaction volume is about $50 \mu 1$, and the electrolysis is completed within $2 \mathrm{~min}$ instead of $4 \mathrm{hr}$ (method d); ${ }^{125}$ I-labeled HSA (em).

(f) The lactoperoxidase method (35); ${ }^{125} \mathrm{I}$ labeled HSA (1).

After the labeling procedures all protein solutions $(a-f)$ were dialyzed against buffer solution to remove any unbound radioactive label. Then the percentage of label bound to the protein was determined by paper chromatographic methods as used by Stern et al. (36) and as described in a technical report of the IAEA (37). These percentages were determined at the end of each experiment.

It appeared, in all cases, that more than $98 \%$ of the label was bound to the protein. The release of the label from the labeled proteins in buffer solution at $310^{\circ} \mathrm{K}$ (Fig. 2) was studied as a function of time. From this figure, it can be concluded that for the ${ }^{99} \mathrm{Tc}-$ labeled proteins only the ${ }^{99 \mathrm{~m}} \mathrm{Tc}$-labeled HSA (e) showed no significant release. Conse-

'Interuniversity Reactor Institute, Delft, Netherlands. Thanks are due to Dr. D. v.d. Hamer for assistance in the experiments. 


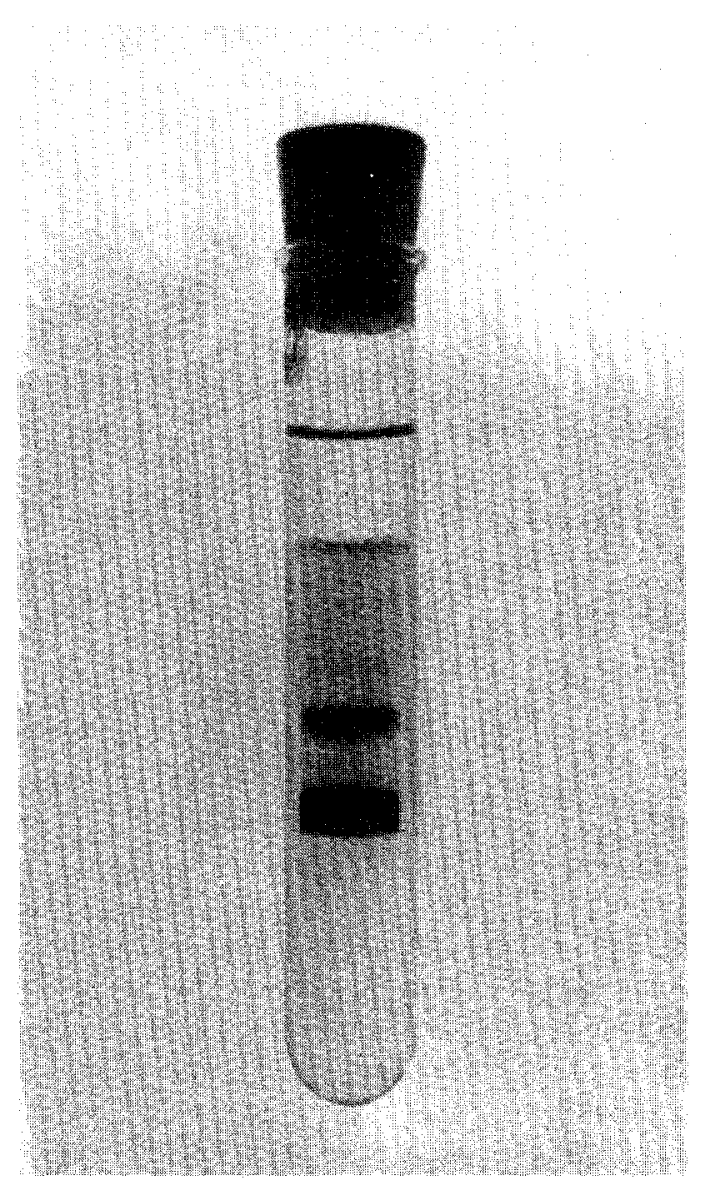

FIG. 3. Electrophoretic pattern of HSA (Sigma, A 9511). Electrophoresis was carried out on polyacrylamide gel at $\mathrm{pH}=7.4,[\mathrm{NaCl}]=0.15 \mathrm{M}$ in phosphate buffer.

quently protein labeling by methods a and $b$ was not further investigated. The ${ }^{125} \mathrm{I}-$ labeled proteins showed no release of the label.

Characterization of proteins. HSA (Sigma, A 9511) was characterized by disc electrophoresis on polyacrylamide gel with a Shannon apparatus; three bands were observed (Fig. 3), which correspond with HSA monomer, dimer, and trimer.

Chromatography using a column packed with Sephadex G-100 showed only the presence of monomer and dimer.

Immunoelectrophoresis using rabbit antihuman serum did not reveal the presence of other proteins.
Labeled HSA ( ${ }^{99 m}$ Tc-labeled HSA(e), ${ }^{125} \mathrm{I}$ labeled HSA(e), ${ }^{125}$ I-labeled HSA(em), or ${ }^{125}$ I-labeled HSA(1)) was mixed with HSA (nonlabeled), and the different mixtures were investigated by disc electrophoresis. It was shown that the radioactivity was present only in the three colored bands, and the amount of radioactivity correlates with the intensity of the color of the bands, indicating that the electrophoretic behavior of the labeled proteins has not changed significantly by the labeling methods. Chromatography of a mixture of ${ }^{125}$ I-labeled HSA (em) and HSA using a Sephadex G-100 column yields two fractions (monomer and dimer) with activities in accordance with the relative protein concentrations.

Immunoelectrophoresis of the same mixture showed that the immunoactivity was not changed by the labeling method.

\section{Methods}

The adsorption experiments were carried out by using two methods:

(i) Adsorption onto PS and SR platelets. With this method only the amount of adsorbed radio-labeled protein can be measured. The total protein concentration in the solution during each adsorption experiment remains almost constant.

(ii) Adsorption onto PS latex. In this case the adsorbed amounts of labeled as well as nonlabeled protein can be measured. The total protein concentration in the solution during each adsorption experiment decreases as a result of the large surface area of the latex.

PS latex was added to a partially ${ }^{125} \mathrm{I}$-labeled protein solution of known concentration. After $24 \mathrm{hr}$ adsorption time, the mixture was centrifuged at $20,000 \mathrm{~g}$. The protein concentration in the supernatant was determined by two methods: (a) Folin-phenol method (11), and (b) by measuring the radioactivity in the solution.

The adsorption experiments with the PScoated surfaces $\left(3.2 \times 10^{-4} \mathrm{~m}^{2}\right)$ and the SR surfaces $\left(2.0 \times 10^{-4} \mathrm{~m}^{2}\right)$ were carried 
out in a thermostated adsorption cell containing four trays in which the samples immersed in buffer solution can be separated from the main solution (Fig. 4).

Contact of the solid surfaces with the liquid-air interface was avoided during the adsorption experiments and the rinsing procedures. This is important because "denaturated" protein layers might be deposited on the surfaces which are studied.

A typical adsorption experiment was performed as follows: the cell (Pyrex glass) was cleaned in a "chromic acid" cleaning mixture and rinsed thoroughly, first with tap water and then with redistilled water. After drying, the cell was connected with a thermostated bath $\left(310^{\circ} \mathrm{K}\right)$ and placed on a magnetic stirrer with buffer solution. The surfaces were attached with nylon ropes to the glass cover and brought into the buffer solution. After temperature equilibration the surfaces were drawn several times through the liquid-air interface in order to remove any air bubbles. Then the trays were lifted and a concentrated, partially labeled protein solution was injected into the stirred solution. During the addition, special care was taken to make sure that the needle was situated well below the liquid-air interface. After complete mixing, stirring was stopped and the trays were lowered to the

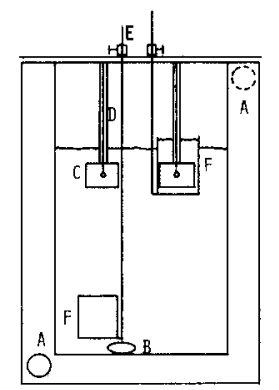

FIG. 4. Thermostated adsorption cell, containing four trays in which samples immersed in buffer solution can be separated from the main solution. A, connection with the thermostated bath; $B$, magnetic stirrer; $C$, surfaces under investigation; $D$, nylon rope in glass tubing; $E$, glass cover; $F$, trays.

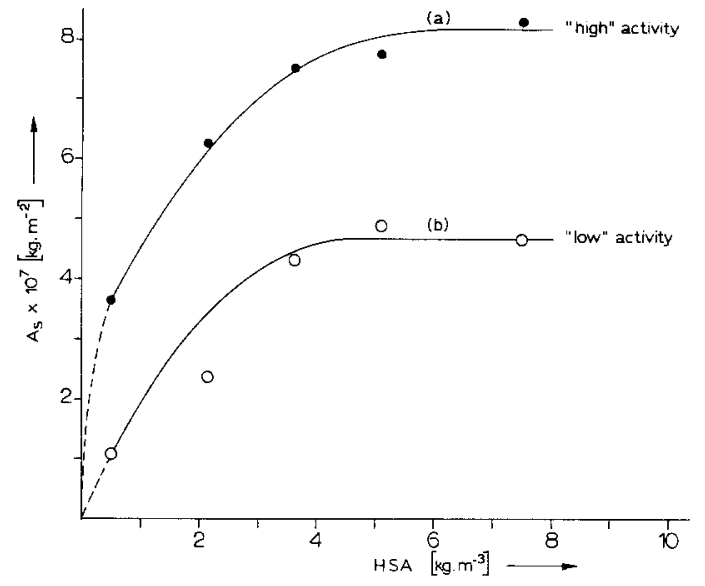

FIG. 5. Surface concentration of ${ }^{99 m}$ Tc-labeled HSA(e) $\left(A_{s}\right)$ on PS as a function of total HSA concentration in the solution $(A+B)$. Concentration ratios of labeled to nonlabeled protein; $C_{1}$ $=1.15 \times 10^{-2}$ and $C_{2}=4.67 \times 10^{-2}$.

bottom, which allows the surfaces to contact the protein solution.

This procedure was developed to avoid a possible contact of the surfaces with a nonhomogeneous protein solution, which might cause deviations in the adsorption data. After the desired adsorption time, the trays were lifted and the glass cover with trays and sample surfaces was placed on a beaker. Then the solution in the trays was displaced by buffer solution until the solution in the trays was free of activity. The trays were lowered and the surfaces were placed into counting tubes.

The measured activity on the surfaces was not affected by further rinsing. The amount of radioactive protein on the surfaces is calculated by comparing the measured radio activity in counts per $180 \mathrm{sec}$ with the activities of the solution samples. The activity was determined with a scintillation counter (Baird Atomic, spectrometer model S 30).

\section{RESULTS}

\section{Adsorption onto PS and SR Platelets}

Figure 5 shows the results of the adsorption of ${ }^{99 m}$ Tc-labeled HSA(e) using two 


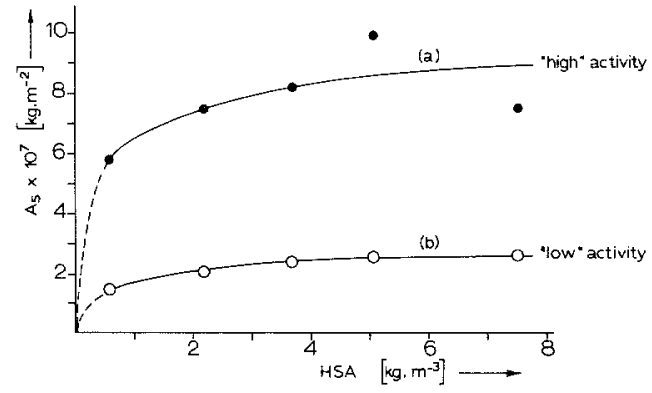

Fig. 6. Surface concentration of ${ }^{99 m}$ Tc-labeled HSA(e) $\left(A_{s}\right)$ on SR as a function of total HSA concentration in the solution $(A+B)$. Concentration ratios of labeled to nonlabeled protein; $C_{1}=1.15$ $\times 10^{-2}$ and $C_{2}=4.76 \times 10^{-2}$.

concentration ratios of labeled to nonlabeled protein, $C_{1}=1.15 \times 10^{-2}$ and $C_{2}$ $=4.76 \times 10^{-2}$ onto PS.

Using Eqs. [18] and [21] we can calculate that in this case $\phi x=66 \pm 20$. This means that the ${ }^{99 m}$ Tc-labeled HSA(e) adsorbs preferentially as compared to nonlabeled HSA. The results of a similar experiment with SR are shown in Fig. 6. Now $\phi x=5.4$ \pm 3.5 . This implies that proteins labeled in the same way show different adsorption behavior upon exposure to different surfaces. ${ }^{125} \mathrm{I}$-labeled HSA(em) was tested in the same way on PS-covered platelets (Fig. 7). In this case $\phi x$ was $1.0 \pm 2.9$ (Eqs. [18] and [21]).

\section{Adsorption onto a PS Latex}

These experiments were carried out with ${ }^{125}$ I-labeled HSA(e), ${ }^{125}$ I-labeled HSA(em), and ${ }^{125}$ I-labeled HSA(1).

Using Eqs. [26] and [27], values of $\phi$ and $\phi_{\text {depl }}$ for the different cases can be calculated. These data are given in Table I.

\section{DISCUSSION}

When labeled proteins are used for adsorption experiments it is necessary to investigate the stability of the bond between the label and the protein molecule. This was done with the different ${ }^{99 \mathrm{~m}} \mathrm{Tc}$ - and ${ }^{125} \mathrm{I}$ labeled HSA preparates.
Figure 2 shows that ${ }^{99 m}$ Tc-labeled HSA (incubation method, i and $\mathrm{im}$ ) is not stable under adsorption conditions. Consequently these compounds were not further investigated. The remaining labeled proteins were characterized by electrophoretic methods. These methods all indicate that the labeled proteins resemble the nonlabeled ones in their electrophoretic behavior and no preferential labeling of HSA monomer, dimer, or trimer was observed.

Subsequently, adsorption experiments were carried out to detect any possible different adsorption behavior of the labeled protein as compared to the nonlabeled. Adsorption experiments with ${ }^{99 m}$ Tc-labeled HSA(e) onto PS and SR platelets (Figs. 5 and 6) show a preferential adsorption of the labeled protein. The preferential adsorption, expressed by $\phi x$ (Eq. [18]) was different for the two polymer surfaces (on PS: $\phi x=66 \pm 20$ and on SR: $\phi x=5.4$ \pm 3.5 ). This means that the difference in adsorption behavior between labeled and nonlabeled protein is a function of the substrate used. Because ${ }^{99 m}$ Tc-labeled HSA(e) shows preferential adsorption it was not used in further experiments.

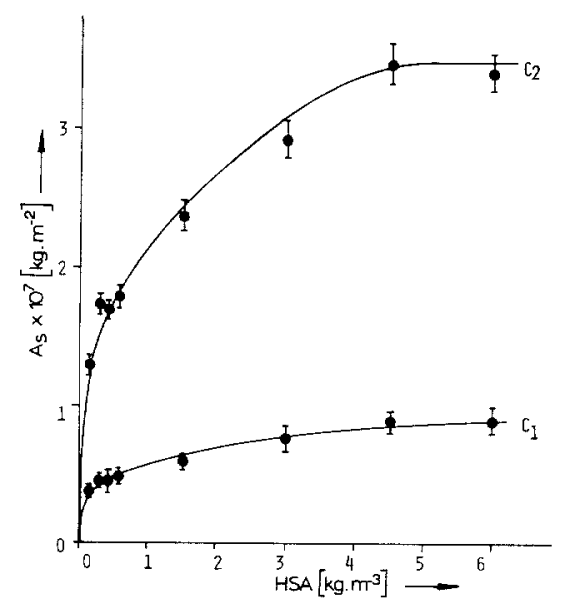

FIG. 7. Surface concentration $\left(A_{s}\right)$ of ${ }^{125}$ I-labeled HSA(em) on PS as a function of total protein concentration in solution $(A+B)$. Concentration ratios of labeled in nonlabeled protein; $C_{1}=1.6$ $\times 10^{-2}$ and $C_{2}=6.4 \times 10^{-2}$. 
TABLE I

Experimental Data for the Adsorption of Differently Labeled Proteins onto PS-Latex ${ }^{a}$

\begin{tabular}{lcccccc}
\hline \multicolumn{1}{c}{ Protein } & $\boldsymbol{A} / \boldsymbol{A}_{0}$ & $\boldsymbol{B} / \boldsymbol{B}_{0}$ & $\phi$ & $\boldsymbol{A} / \boldsymbol{B}$ & $\boldsymbol{A}_{\mathrm{s}} / \boldsymbol{B}_{\mathrm{s}}$ & $\phi_{\text {depl }}$ \\
\hline${ }^{125}$ I-labeled HSA(e) & 0.362 & 0.488 & 1.42 & 0.0119 & 0.0199 & 1.67 \\
${ }^{125}$ I-labeled HSA(em) & 0.421 & 0.520 & 1.32 & 0.0129 & 0.0193 & 1.50 \\
${ }^{125}$ I-labeled HSA(l) & 0.438 & 0.528 & 1.29 & 0.0134 & 0.0192 & 1.43 \\
\hline
\end{tabular}

${ }^{a}$ Adsorption after $24 \mathrm{hr} . T=298^{\circ} \mathrm{K}, \mathrm{pH}=7.4,[\mathrm{NaCl}]=0.15 \mathrm{M}$, phosphate buffer.

For ${ }^{125}$ I-labeled HSA(e) on PS (Fig. 7), $\phi x$ is $1.0 \pm 2.9$, indicating that in this case the test method is not sensitive enough to conclude whether preferential adsorption takes place. This method was also used by Brash et al. (27) who measured the adsorption of ${ }^{125}$ I-labeled HSA [labeled by the iodine monochloride method of MacFarlane (38) onto polyethylene (PE)]. Also in that case the method is not sensitive enough to exclude preferential adsorption.

Horbett et al. (39) measured the preferential adsorption of hemoglobin compared to other proteins onto $\mathrm{PE}$, using radio-labeled proteins.

Lee et al. $(15,26)$ and Dezelićz et al. (7) also used different ${ }^{125}$ I-labeled proteins for competitive and kinetics adsorption experiments. The possible influence of the labeling on the adsorption behavior of the proteins was not investigated. When $\phi x$ is close to 1 , a more accurate method for the determination of possible preferential adsorption is required. This was achieved by using as the substrate a PS latex with a high specific surface.

Now the adsorption causes a significant decrease of the protein concentration in the solution. The decrease of the total protein concentration $[A+B]$ in the solution after $24 \mathrm{hr}$ can be measured spectrophotometrically, and the decrease of the concentration of the labeled protein $[A]$ by measuring the radioactivity of the solution. The preferential adsorption parameters $\phi$ and $\phi_{\text {depl }}$ can now be calculated by using Eqs. [26] and [27].

Table I shows values of $\phi$ and $\phi_{\text {depl }}$ for
${ }^{125}$ I-labeled HSA, labeled in different ways, which can be measured with an accuracy of about $10 \%$.

All labeled proteins show values of $\phi$ and $\phi_{\text {depl }} \neq 1$ indicating preferential adsorption. It is also shown that $\phi \neq \phi_{\text {depl }}$ indicating irreversible adsorption. In conclusion, when labeled proteins are used for adsorption studies it is necessary to determine whether preferential adsorption occurs, even when the bond between the label and the protein is stable under experimental conditions and when the labeled proteins show the same electrophoretic behavior as the nonlabeled ones.

\section{ACKNOWLEDGMENT}

The authors like to thank Ir. F. J. Wubben for his contribution to part of the experimental work.

\section{REFERENCES}

1. Mason, R. G., in "Erythrocytes, Thrombocytes, Leucocytes," p. 263. Georg Thieme, Stuttgart, 1973.

2. Zucker, M. B., and Vroman, L., Proc. Soc. Exp. Biol. Med. 131, 318 (1969).

3. Lyman, D. J., Thromb. Diath. Heamorrh. Suppl. 42, 109 (1970).

4. Kim, S. W., Lee, R. G., Oster, H., Coleman, D., Andrade, J. D., Lentz, D. J., and Olscen, D., Trans. Amer. Soc. Artif. Int. Organs 20, 449 (1974).

5. Bull, H. B., Arch. Biochem. Biophys. 68, 102 (1957).

6. MacRitchie, F., J. Colloid Interface Sci. 38, 484 (1972).

7. Dezelićz, G., Dezelićz, N., and Telisman, Z., Eur. J. Biochem. 23, 575 (1973).

8. Lijklema, J., and Norde, W., Croat. Chem. Acta 45, 67 (1973). 
9. Oreskes, I., and Singer J. M., J. Immunol. 86, 338 (1961).

10. Bull, H. B., Biochim. Biophys. Acta 19, 464 (1956),

11. Lowrey, O. H., Rosebrough, N. J., Farr, A. L., and Randall, R. J., J. Biol. Chem. 193, 265 (1951).

12. Dillman, W. J., and Miller, I. F., J. Colloid Interface Sci. 44, 221 (1973).

13. Kihara, H. K, and Kuno, H., Anal. Biochem. 24, 96 (1968).

14. Brash, J. L., and Lyman, D. J., J. Biomed. Mater. Res. 3, 175 (1969).

15. Lee, R. G., and Kim, S. W., J. Biomed. Mater. Res. 8, 251 (1974).

16. Morrissey, B. W., and Stromberg, R. R., J Colloid Interface Sci. 46, 152 (1974).

17. Brash, J. L., and Lyman, D. J., in "Chemistry of Biosurfaces" (M. L. Hair, Ed.), p. 177. M. Dekker, New York, 1971.

18. McMillin, C. R., and Walton, A. G., J. Colloid Interface Sci. 48, 345 (1974).

19. Vroman, L., Thromb. Diath. Haemorrh. 10, 455 (1964).

20. Vroman, L., and Lukosevicius A., Nature (London) 204, 701 (1964).

21. Vroman, L., and Adams, A. L., Thromb. Diath. Haemorrh. 18, 510 (1962).

22. Vroman, L., and Adams, A. L., J. Biomed. Mater. Res. 3, 43 (1969).

23. Vroman, L., and Adams, A. L., J. Polymer Sci. part C, 34, 159 (1971).

24. Klings, M., Adams, A. L., and Vroman, L., Thromb. Res. 1, 507 (1972).
25. Bateman, J. B., and Adams, E. D., J. Phys. Chem. 61, 1039 (1957).

26. Lee, R. G., Adamson, C., and Kim, S. W. Thromb. Res. 4, 485 (1974).

27. Brash, J. L., Uniyal, S., and Samak, Q., Trans. Amer. Soc. Artif. Int. Organs 20, 69 (1974).

28. Falb, R. D., Takahashi, M. T., Grobe, G. A., and Leininger, R. I., J. Biomed. Mater. Res. 1, 239 (1967)

29. Goodwin, J. W., Hearn, J., Ho, C. C., and Ottewill, R. H., Colloid Polymer Sci. 252, 464 (1974).

30. Krugers Dagneaux, P. G. L. C., and Klein Elhorst, J. T., Pharm. Weekblad 109, 1177 (1974).

31. Stern, H. S., McAffee, J. G., and Zolle, I., in "Radio-active Pharmaceuticals," p. 359. U.S. Atomic Energy Commission, 1966.

32. Benjamin, P. P., Regali, A., and Friedell, H, J. Nucl. Med. 11, 147 (1970),

33. Benjamin, P. P., J. Nucl. Med. 13, 172 (1972).

34. Rosa, U., Scassellati, G. A., Pennisi, F., Riccioni, N., Giagnoni, P., and Giordani, R., Biochim. Biophys. Acta 86, 519 (1964).

35. David, G. S., and Reisfeld, R. A., Biochemistry 13, 1014 (1974).

36. Stern, H. S., Zolle, I., and McAffee, J. C., Int. J. Appl. Radiat. Isotop. 16, 283 (1965).

37. Junta de Energia Nuclear, in "Radio-isotope Production and Quality Control, p. 879. IAEA, Technical Report Series, No. 128, 1971.

38. McFarlane, A. S., Nature (London) 182, 53 (1958).

39. Horbett, T. A., Weathersby, P. K., and Hoffman, A. S., J. Bioeng. 1, 6I (1977). 